\title{
Use of gamification to enhance curiosity and engagement through feedback strategies
}

\author{
Anupam Makhija, Meena Jha, Deborah Richards, Ayse Bilgin \\ Central Queensland University, Central Queensland University, Macquarie University, Macquarie University
}

Curiosity is a significant educational component behind human learning and is vital for a learner to sustain motivation and engagement in both face-to-face and online learning environments. Positive feedback has the potential to support learning by enhancing competence, confidence, and curiosity. Informative feedback at the right time is the sought-after goal in traditional classrooms and is equally important for the learning design within a digital educational environment. Individual differences such as personality, gender, learning style, and curiosity trait can play a crucial role in how feedback is received and acquired knowledge is demonstrated in a different context by a learner. This paper proposes to exploit the benefits of positive feedback in a statistics game by establishing a connection between feedback and curiosity through the lens of the selfdetermination theory of motivation. It presents a work-in-progress psychological theory-based conceptual framework to foster curiosity by means of game-based learning and gamification approaches.

Keywords: Statistical Education, Self-Determination Theory, Curiosity, Motivation, Engagement, Game-Based Learning, Gamification, Feedback

\section{Introduction and Background}

Curiosity has been conceptualised as an integral component of the learning process and generates motivation and well-being with higher levels of engagement in learners to help achieve full potential in a learning environment (Garrosa, 2017; Stumm et al., 2011). In the recent era, the ubiquitous existence of technology has shifted the focus from traditional classrooms to integrated digital learning environments including game-based mechanics with a capacity to elicit curiosity and motivation (Alsawaier, 2018; Fahimnia et al., 2019). Instructional designers have considered feedback as one of the critical elements to influence learning (Sullivan \& Higgins, 1983) that can be utilised in a game to stimulate curiosity and motivation in learners (KickmeierRust et al., 2014). Since the advent of gamified educational platforms, the learning design of such an environment involves consideration of the importance of good feedback and maximisation of the quality of feedback to make it more effective and relevant (Ringtved \& Corrin, 2016).

The research on curiosity was initiated in the 1950s as a neurophysiological term that encourages an individual to engage in exploratory behaviour to gain knowledge in different environments (Berlyne, 1957).

Loewenstein (1994) defines curiosity as an epistemic emotion generated through a knowledge gap while some researchers consider curiosity as another form of intrinsic motivation (Deci \& Ryan 1985; White 1959).

Informative feedback can be used as a mechanism for satisfying a curious learner (Malone, 1981). Information gap theory formulated by Loewenstein (1994) suggests that the intensity of curiosity becomes higher when the information gap is smaller (Litman et al., 2005). The feeling of deprivation caused by missing information can be reduced by filling the knowledge gap with the presence of appropriate feedback (Arnone, 1995). Engagement can be represented as a positive motivational state characterised by effort, passion, and dedication to learn new things (Garrosa, 2017).

According to Fox and Hoffman (2002), the level of engagement and effort increases if a learner feels that they are close to their specific goal. Self-Deterministic Theory (SDT) of motivation posits that support for competence through positive feedback facilitates intrinsic motivation, which in turn is associated with improved curiosity and academic engagement (Deci \& Ryan, 2000). The inclusion of positive feedback can positively impact the psychological need for satisfaction and intrinsic motivation in a gamification environment (Burgers, 
2015). For this study, feedback is defined as information that is communicated to an individual in consequence of their performance to improve their learning (Hattie, 2007).

Gamification is emerging as a popular trend attracting educational researchers because of their capability to support learners' curiosity, motivation, and engagement through key mechanisms in an academic context (Subhash \& Cudney, 2018) while game-based learning refers to an approach of using games to make learning more fun and interesting (Kickmeier-Rust et al., 2014). Past research has reported that many students experience anxiety while studying statistics and demonstrate low academic performance (Onwuegbuzie et al., 2010). Gamebased learning with gamification approaches can potentially help to reduce students' statistical anxiety. According to the study conducted by Kickmeier-Rust et al. (2014), positive and meaningful feedback delivered in-game can successfully help direct learning through game intervention strategies. Furthermore, another research evidence reports that players expressed positive emotions after receiving constructive feedback following a failure in the gamified environment (Alsaweir, 2018).

Additionally, researchers have attempted to investigate the effectiveness and preferences of feedback based on individual differences such as personality type (Swift \& Peterson, 2018), learning style (Tasdemir \& Arslan, 2018), and motivational behaviour (Lin et al., 2013). Buckley and Doyle (2014) reported in their study that an individual's intrinsic motivation level in game-based environment can positively influence learners' performance. There is no adequate evidence base to support the effectiveness of learning style as a valuable pedagogical tool, but it is worthwhile to design feedback strategies around this notion (Pashler et al., 2008).

Research emphasises the significance of the need for teachers to understand a learner's progress during their learning process and similarly it is essential for a learner to understand their own progress through the feedback received by them (Hattie \& Timperley, 2007). Designing appropriate, effective, and balanced feedback has been a challenging task for educationalists (Boud, 2013). The findings from relevant research studies suggest that designing good computer-based feedback is not a straightforward task and can depend on many factors investigated during past decades (Wang et al., 2019). Some of these factors include the timing of feedback, immediate or delayed feedback (Schroth, 1992), amount of the feedback (Moreno, 2004), or the focus of the feedback (Brookhart, 2008). There is no one size fits all approach to design the feedback that has proven to be effective for all learners and in all situations as these considerations vary according to circumstances and learners' feedback preferences (Tasdemir \& Arslan, 2018). Feedback can have disparate effects on curiosity and intrinsic motivation based on how it is delivered, how the recipient interprets the feedback, and how the behaviour is related to the feedback provided to learners.

This research aims to develop a conceptual framework to enhance curiosity and motivation in a game-based environment through positive feedback by understanding the implications of individual differences such as personality, gender, learning style, and curiosity trait. The theoretical lens to be used will be SDT, thus seeking to raise curiosity through providing feedback to increase intrinsic motivation towards improving learner's competency within such an environment. The proposed study will be based on a statistics game called 'Understanding the World with Statistics' and will address the following research questions related to curiosity, engagement, and feedback:

- What is the link between curiosity, engagement, and academic performance?

- What impact does positive feedback have on the curiosity level of a learner based on individual differences such as personality, gender, learning style, and curiosity trait?

Some key concepts are discussed further in the following sections that are important to provide more insight into our research study. Section 2 discusses the research design; section 3 describes the information about the statistics game to implement the suggested framework to foster curiosity and engagement. This section also discusses the intervention design to be used for our study. The research gap and conclusions are discussed in the last section.

\section{Research Design}

In this research, we are building and evaluating an artefact designed in the form of a statistics game to understand the role of feedback in learning by using the design science research (DSR) approach. There has been an increasing interest in DSR from the Information Systems (IS) discipline recently as it focuses on building and evaluating innovative artefacts in the form of a new model, methods, or systems as a solution to research problems (Hevner, 2007). The fundamental principle of DSR is to understand a design problem and 
acquire the solution through building an application as an artefact. These characteristics make DSR the appropriate research methodology for the proposed study as the goal of this research study is to build and evaluate the game artefact to understand the role of feedback in enhancing the level of curiosity within a gamebased environment.

The DSR framework for our study consists of a three-phase cycle referred to as relevance cycle, rigor cycle, and central design cycle. The relevance cycle bridges the contextual environment of the research project with the design science activities. The rigor cycle connects the design science activities with the knowledge base of scientific foundations, experience, and expertise that informs the research project. The central design cycle iterates between the core activities of building and evaluating the design artefacts, and processes of the research (Hevner, 2007). Offermann et al. (2009) suggest structuring the DSR process as three phases namely "problem identification", "solution design", and "evaluation" with interacting activities for individual phases. Each phase is related to one of the cycles of the DSR framework as described below:

Phase 1: The first phase of this research relates to the relevance cycle, which begins with identifying and representing opportunities and problems in the form of research questions within an application domain. The problem identification phase consists of three steps: identify the problem, literature research, and pre-evaluate relevance. The purpose of this phase is to specify the research questions and verify the practical relevance to offer a solid foundation for further research process (Offermann et al., 2009).

Phase 2: The second phase is the solution design phase and relates to the central design cycle. The central design cycle is about building and evaluating innovative artefact design alternatives to achieve the desired solution. In the proposed research, the data collected through a game-based study will be analysed. Based on the data analysis, solutions will be developed to the identified problems, which can then be implemented as modifications in the game-based learning environment.

Phase 3: The third phase is the evaluation phase and is about rigorous and thorough evaluation and testing of the designed solution using diverse approaches, calling for multiple iterations of the design cycle before contributions are sent as output into the relevance cycle and the rigor cycle (Hevner, 2007). The output of these cycles is fed into the design phase where a solution is constructed. Data is collected and analysed to ascertain the effectiveness of the implemented solution.

\section{Intervention Design using Game-Based Environment}

Figure 1 shows the conceptual framework, based on Self-Deterministic Theory (SDT), designed to provide positive and informative feedback to satisfy learners' need for competence through enhancing curiosity and intrinsic motivation leading to an improved engagement for maximising learning.

Figure 1. A conceptual framework to enhance curiosity and motivation using positive and informative feedback

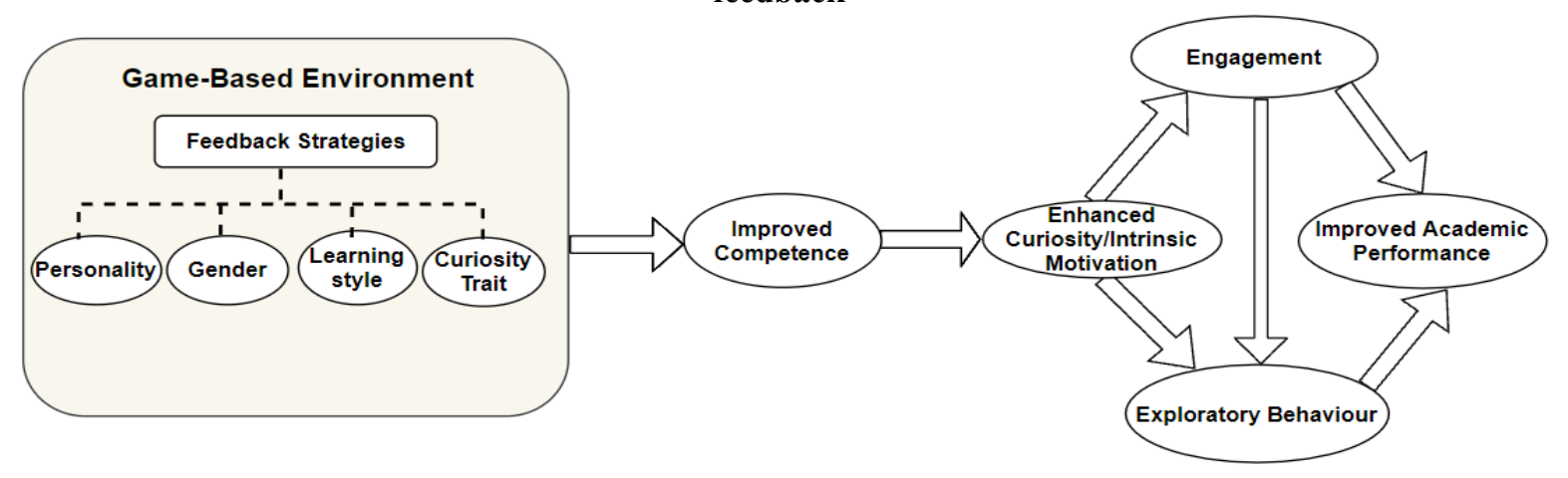

We have developed a game to teach statistics by stimulating the player's curiosity to learn statistical concepts. The purpose is to motivate players with the game-based environment and help them in long-term learning. The proposed statistical game represents a fictitious museum setting game in which a player interacts with a set of museum artefacts and a curator character to teach them statistical concepts through real-world statistics datasets for the United Nations Sustainable Development Goals (Sustainable Development Goals, 2021). The game design is based on psychological concepts such as novelty, relevance, optimal challenge, and presence of feedback along with features that make the game more fun and interesting. 
This game consisting of three levels is developed by researchers on Unity 3D platform to teach key concepts within statistics. It helps learners identify why a certain formula, approach, or method is used for a given problem, instead of teaching statistical procedures first and finding the problems to apply the procedures. The player starts their exploration at level 1, the ground floor which introduces the basic statistics concepts like Mean, Mode, Median, and Standard Deviation. As the player advances through levels 2 and 3 they are presented with higher-level statistical concepts such as hypothesis testing, correlation, and linear regression. The intended learning outcomes for this game are to stimulate curiosity through triggering effective and informative feedback and test the learner's ability to provide statistical analysis for real-world problems such as "What factors reduce poverty?".

Figure 2 shows a screenshot of the game for the research study. The data collected is self-reported by the participants through their interaction with the game. The study will start with a demographic questionnaire including questions for collecting participants' information related to gender, cultural group, age, learning style, and the number of hours they spend playing computer games per week. The Participants will complete the Ten Item Personality Instrument (TIPI) to measure the Big-Five personality traits (Openness, Conscientiousness, Extroversion, Agreeableness, Neuroticism), also called OCEAN collectively (Goldberg, 1990; Gosling et al., 2003). The participants will also be asked to complete the Melbourne Curiosity Inventory (MCI) questionnaire to measure the level of learners' curiosity before and after playing the game. The multiple-choice quizzes (MCQ) will be used at each level to measure learning gains in terms of the number of questions answered correctly in the game.

Figure 2. A screenshot of Statistical Gaming System

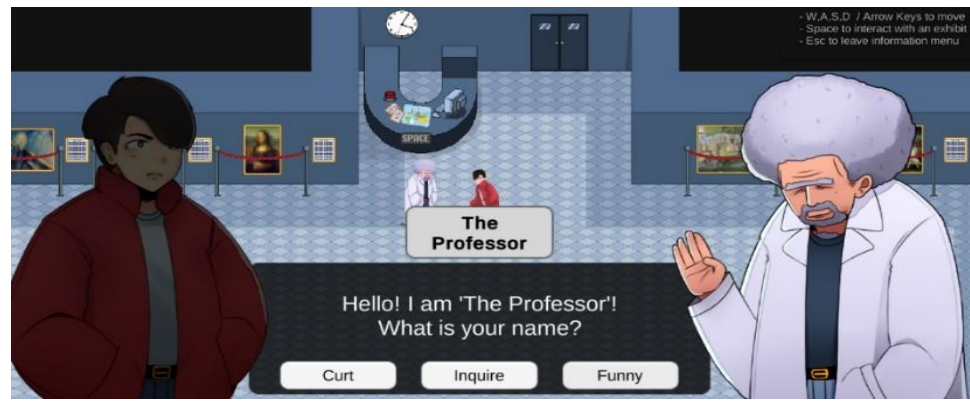

\section{Conclusion and Future Work}

Curiosity is an aspect of intrinsic motivation that has great potential to benefit academic learning. To develop a cohesive model to enhance curiosity in a game-based learning platform, it is essential to investigate the impact of feedback on learners' performance based on their individual differences and help develop an internal drive to achieve their learning goals.

In this paper, we presented the relationship between feedback and curiosity through the lens of psychological theories. It also discusses the role games can play in eliciting curiosity and improving engagement by providing informative and positive feedback, and how the learners with individual differences will be able to effectively receive and interpret the feedback supplied to them. By being aware of individual learning needs, educators can demonstrate that they are not only guiding learners by providing meaningful feedback but also satisfying the psychological need of competency and fostering a level of curiosity and motivation for deeper engagement through their learning journey.

\section{References}

Alsawaier, R. (2018). The effect of gamification on motivation and engagement. The International Journal of Information And Learning Technology, 35(1), 56-79. https://doi.org/10.1108/IJILT-02-2017-0009

Arnone, M. P., \& Small, R. V. (1995). Arousing and sustaining curiosity: Lessons from the ARCS model. In 17th Proceedings of the Annual National Conference of the Association of Educational Communications and Technology (AECT), Anaheim, CA. 1-15.

Berlyne, D. E. (1957). Conflict and information-theory variables as determinants of human perceptual curiosity. Journal of Experimental Psychology, 53(6), 399-415. https://doi.org/10.1037/h0049194 
Boud, D., \& Molloy, E. (2013). Rethinking models of feedback for learning: the challenge of design. Assessment \& Evaluation in HigherEeducation, 38(6), 698-712. https://doi.org/10.1080/02602938.2012.691462

Brookhart, S. M. (2008). How to give effective feedback to your students. Alexandria, VA: Association for Supervision and Curriculum Development (ASCD).

Buckley P., Doyle E. (2014). Gamification and student motivation. Interactive Learning Environments, 24(6), 1162-1175. https://doi.org/10.1080/10494820.2014.964263

Burgers, C., Eden, A., Van Engelenburg, M. D., \& Buningh, S. (2015). How feedback boosts motivation and plays in a brain-training game. Computers in Human Behavior, 48, 94-103. https://doi.org/10.1016/j.chb.2015.01.038

Deci, E. L., \& Ryan, R. M. (1985). Conceptualizations of Intrinsic Motivation and self-determination. BT Intrinsic Motivation and Self-Determination in Human Behavior. In E. L. Deci \& R. M. Ryan (Eds.), Boston: Springer US, 11-40. https://doi.org/10.1007/978-1-4899-2271-7 2.

Deci, E. L., \& Ryan, R. M. (2000). The "what" and "why" of goal pursuits: Human needs and the selfdetermination of behavior. Psychological Inquiry, 11, 227-268. https://doi.org/10.1207/S15327965PLI1104_01

Fahimnia, F., Naghshineh, N. and Mirhosseini, F. (2019). Gamified e-learning in higher education: A systematic review of the literature, Journal of Technology of Education, 13(4), 875-887.

Fox, S., \& Hoffman, M. (2002). Escalation behavior as a specific case of goal-directed activity: A persistence paradigm. Basic and Applied Social Psychology, 24(4), 273-285. https://doi.org/10.1207/S15324834BASP2404_3

Garrosa, E., Blanco-Donoso, L. M., Carmona-Cobo, I., \& Moreno-Jiménez, B. (2017). How do curiosity, meaning in life, and search for meaning predict college students' daily emotional exhaustion and engagement?. Journal of Happiness Studies, 18(1), 17-40. https://doi.org/10.1007/s10902-016-9715-3

Goldberg, L. R. (1990). An alternative "description of personality": the big-five factor structure. Journal of Personality and Social Psychology, 59(6), 12-16. https://doi.org/10.1037/0022-3514.59.6.1216

Gosling, S. D., Rentfrow, P. J., \& Swann, W. B. (2003). A very brief measure of the Big-Five personality domains. Journal of Research in Personality, 37(6), 504-528. https://doi.org/10.1016/S00926566(03)00046-1

Hattie, J., \& Timperley, H. (2007). The power of feedback. Review of Educational Research, 77(1), 81-112. https://doi.org/10.3102/003465430298487

Hevner, A. R. (2007). A three-cycle view of design science research. Scandinavian Journal of Information Systems, 19(2), 87-92.

Kickmeier-Rust, M. D., Hillemann, E. C., \& Albert, D. (2014). Gamification and smart feedback: Experiences with a primary school level math app. International Journal of Game-Based Learning (IJGBL), 4(3), 35-46. https://doi.org/10.4018/ijgbl.2014070104

Lin, L., Atkinson, R., Christopherson, R., Joseph, S., \& Harrison, C. (2013). Animated agents and learning: Does the type of verbal feedback they provide matter? Computers \& Education, 67, 239-249. https://doi.org/10.1016/j.compedu.2013.04.017

Litman, J. A., Hutchins, T. L., \& Russon, R. K. (2005). Epistemic curiosity, feeling-of-knowing, and exploratory behaviour. Cognition and Emotion, 19, 559-582. https://doi.org/10.1080/02699930441000427

Loewenstein, G. (1994). The psychology of curiosity: A review and reinterpretation. Psychological Bulletin, 116(1), 75-98. https://doi.org/10.1037/0033-2909.116.1.75

Malone, T. W. (1981). Toward a theory of intrinsically motivating instruction. Cognitive science, 5(4), 333-369. https://doi.org/10.1207/s15516709cog0504_2

Moreno, R. (2004). Decreasing cognitive load for novice students: Effects of explanatory versus corrective feedback in discovery-based multimedia. Instructional Science, 32, 99-11. https://doi.org/10.1023/B:TRUC.0000021811.66966.1d

Naylor, F. D. (1981). A state-trait curiosity inventory. Australian Psychologist, 16(2), 172-183. https://doi.org/10.1080/00050068108255893

Offermann, P., Levina, O., Schönherr, M., \& Bub, U. (2009). Outline of a design science research process. In Proceedings of the 4th International Conference on Design Science Research in Information Systems and Technology, 1-11. https://doi.org/10.1145/1555619.1555629

Onwuegbuzie, A. J. (2000). Statistics anxiety and the role of self-perceptions. The Journal of Educational Research, 93(5), 323-330. https://doi.org/10.1080/00220670009598724

Pashler, H., McDaniel, M., Rohrer, D., \& Bjork, R. (2008). Learning styles: Concepts and evidence. Psychological Science in the Public Interest, 9(3), 105-119. https://doi.org/10.1111/j.15396053.2009.01038.x 
Ringtved, U., Milligan, S., \& Corrin, L. (2016). Learning design and feedback processes at scale: stocktaking emergent theory and practice. In Proceedings of the Sixth International Conference on Learning Analytics \& Knowledge, 479-480. https://doi.org/10.1145/2883851.2883856

Schroth, M. L. (1992). The effects of delay of feedback on a delayed concept formation transfer task. Contemporary Educational Psychology, 17, 78-82. https://doi.org/10.1016/0361-476X(92)90048-4

Subhash, S., \& Cudney, E. (2018). Gamified learning in higher education: A systematic review of the literature. Computers In Human Behavior, 87, 192-206. https://doi.org/10.1016/j.chb.2018.05.028

Sullivan, H., \& Higgins, N. (1983). Teaching for competence. New York, US: Teachers College Press.

Sustainable Development Goals | United Nations Development Programme. Undp.org. (2021). Retrieved 24 June 2021, from https://www.undp.org/sustainable-development-goals.

Swift, V., \& Peterson, J. B. (2018). Improving the effectiveness of performance feedback by considering personality traits and task demands. PloS One, 13, e0197810. https://doi.org/10.1371/journal.pone.0197810

Tasdemir, M. S., \& Arslan, F. Y. (2018). Feedback preferences of EFL learners with respect to their learning styles. Cogent Education, 5(1), 1-17. https://doi.org/10.1080/2331186X.2018.1481560.

Wang, Z., Gong, S. Y., Xu, S., \& Hu, X. E. (2019). Elaborated feedback and learning: Examining cognitive and motivational influences. Computers \& Education, 136, 130-140. https://doi.org/10.1016/j.compedu.2019.04.003

White, R. W. (1959). Motivation reconsidered: The concept of competence. Psychological Review, 66, $297-333$. https://doi.org/10.1037/h0040934

Makhija, A., Jha, M., Richards, D., \& Bilgin, A. (2021). Use of gamification to enhance curiosity and engagement through feedback strategies. In Gregory, S., Warburton, S., \& Schier, M. (Eds.), Back to the Future - ASCILITE '21. Proceedings ASCILITE 2021 in Armidale (pp. 137-142). https://doi.org/10.14742/ascilite2021.0118

Note: All published papers are refereed, having undergone a double-blind peer-review process.

The author(s) assign a Creative Commons by attribution licence enabling others to distribute, remix, tweak, and build upon their work, even commercially, as long as credit is given to the author(s) for the original creation.

(C) Makhija, A., Jha., M, Richards, D., \& Bilgin, A. 2021 